\title{
New advantages of the combined GPS and GLONASS observations for high-latitude ionospheric irregularities monitoring: case study of June 2015 geomagnetic storm
}

Iurii Cherniak ${ }^{1,2^{*}}$ (1) and Irina Zakharenkova ${ }^{2,3}$

\begin{abstract}
Monitoring, tracking and nowcasting of the ionospheric plasma density disturbances using dual-frequency measurements of the Global Positioning System (GPS) signals are effectively carried out during several decades. Recent rapid growth and modernization of the ground-based segment gives an opportunity to establish a great database consisting of more than 6000 stations worldwide which provide GPS signals measurements with an open access. Apart of the GPS signals, at least two-third of these stations receive simultaneously signals transmitted by another Global Navigation Satellite System (GNSS) — the Russian system GLONASS. Today, GLONASS signal measurements are mainly used in navigation and geodesy only and very rarely for ionosphere research. We present the first results demonstrating advantages of using several independent but compatible GNSS systems like GPS and GLONASS for improvement of the permanent monitoring of the high-latitude ionospheric irregularities. For the first time, the high-resolution twodimensional maps of ROTI perturbation were made using not only GPS but also GLONASS measurements. We extend the use of the ROTI maps for analyzing ionospheric irregularities distribution. We demonstrate that the meridional slices of the ROTI maps can be effectively used to study the occurrence and temporal evolution of the ionospheric irregularities. The meridional slices of the geographical sectors with a high density of the GPS and GLONASS measurements can represent spatio-temporal dynamics of the intense ionospheric plasma density irregularities with very high resolution, and they can be effectively used for detailed study of the space weather drivers on the processes of the ionospheric irregularities generation, development and their lifetimes. Using a representative database of $\sim 5800$ ground-based GNSS stations located worldwide, we have investigated the occurrence of the high-latitude ionospheric plasma density irregularities during the geomagnetic storm of June 22-23, 2015.
\end{abstract}

Keywords: GPS, GLONASS, Plasma irregularities, ROTI, High-latitude ionosphere, Geomagnetic storm

\section{Introduction}

The techniques based on the transionospheric radio waves propagation, in particular satellite navigation signals, are effectively used for monitoring and investigation of the main parameters of the ionospheric plasma irregularities. It is known that radio signals passing through the ionosphere suffer varying degrees of rapid variations of their amplitude and phase signal fluctuations, referred

\footnotetext{
*Correspondence: tcherniak@ukr.net

1 space Weather Laboratory, Kharkiv, Ukraine

Full list of author information is available at the end of the article
}

to as scintillations, created by random fluctuations of the medium's refractive index, caused by plasma density gradients inside the ionosphere (e.g., Tsunoda et al. 1985; Basu et al. 1988; Aarons 1997; Prikryl et al. 2012). At high latitudes, these gradients are mostly caused by plasma processes associated with dynamic auroral processes, such as energetic particle precipitation and high-speed plasma convection (Keskinen and Ossakow 1983). Many researchers have used GPS signals to study ionospheric processes (e.g., Pi et al. 1997; Aarons and Lin 1999; Valladares et al. 2004; Jakowski et al. 2008, 2012; Tiwari et al. 2013; Prikryl et al. 2014; Cherniak and Zakharenkova 
2015; van der Meeren et al. 2014; Jacobsen and Andalsvik 2016). Recently, Cherniak and Zakharenkova (2016a) applied data of the GPS receivers onboard five low earth orbit satellites to examine the occurrence of the topside ionospheric irregularities under the geomagnetic storm conditions and to compare them with effects registered concurrently in the ground-based GPS data.

The number of the ground-based receivers within the global and regional networks grew significantly from several hundreds worldwide in the 1990s to more than 6000 stations today. These networks provide continuous measurements of navigation signals parameters and open access to their databases. In addition to the increase in the number of the ground-based stations, the GPS constellation was modernized by the addition of satellites in the GPS-IIF series. Other GNSS like the Russian GLONASS, the European GALILEO and the Chinese Beidou systems increased the number of satellites placed into orbit. Further development of the multi-system GNSS constellations and modernization of the ground-based receivers to be able to track multi-frequency and multisystem GNSS signals provide more opportunities for ionospheric research in the near future.

At the moment, the second fully deployed GNSS is the Russian system-GLONASS (GLObal Navigational Satellite System) (see Hofmann-Wellenhof et al. 2008; ICD-GLONASS 2008; Jeffrey 2015). The full orbital constellation consists of 24 satellites into three orbit planes. The orbit altitude is $\sim 19,100 \mathrm{~km}$ above the Earth's surface. A significant advantage of the GLONASS, as compared to the GPS, is that the GLONASS has an orbit inclination of $\sim 65^{\circ}$, that is ten degree higher than the GPS orbit inclination. This feature is important for the high-latitude region, where a multi-system GNSS receiver can track the GLONASS navigation signals for much longer time and with higher elevation angles than GPS ones. The number of the ground-based receivers able to track both GPS and GLONASS signals has been increased significantly in last years. In the present paper, we demonstrate the advantages of the multi-constellation measurements for high-latitude ionospheric irregularities monitoring for the case study of the June 2015 geomagnetic storm.

\section{Case study: the summer solstice $\mathbf{2 0 1 5}$ geomagnetic storm}

The Summer Solstice 2015 Event (21-24 June 2015) was selected for the special VarSITI data analysis before the SCOSTEP-WDS September 2015 workshop. This severe geomagnetic storm occurred on the summer solstice day of June 22, 2015, and caused a strong response in the ionosphere-plasmasphere-magnetosphere system. Figure 1 shows the variations of the interplanetary and geomagnetic parameters from the OMNI database during
June 20-24, 2015. A series of three coronal mass ejections (CMEs) arrived at the Earth at 16:45 UT on June 21, 05:45 UT on June 22 and 18:30 UT on June 22, 2015. Baker et al. (2016) also reported about the sudden loss of energetic particles due to the large solar wind dynamic pressure increase on June 22, 2015, after an arrival of the strong interplanetary shock and the CME passage. The sudden storm commencement was registered at 18:33 UT on June 22, 2015, followed by a SYM-H increase to $\sim 88 \mathrm{nT}$ at 18:37 UT. The SYM-H index dropped to the value of $-139 \mathrm{nT}$ at 20:17 UT. At this time, the southward excursion of the IMF $\mathrm{Bz}$ component reached the value of $-39 \mathrm{nT}$ at 19:23 UT and then turned northward and remained largely northward for several hours. After $\sim 01: 50$ UT on 23 June the IMF Bz turned southward and remained negative until 05:40 UT. During this period, the second main phase of the storm developed and the negative excursion of the SYM-H index reached its peak value of $-208 \mathrm{nT}$ at 04:27 UT on June 23, 2015. The auroral electrojet (AE) index depicts an occurrence of several periods of auroral activity intensification from $\sim 06$ UT on 22 June and until $\sim 15$ UT on 23 June. The observed $\mathrm{AE}$ peaks were correlated with the IMF Bz southward turnings and increases of the solar wind speed and pressure. The $\mathrm{AE}$ index characterizes the magnetospheric energy deposed to the auroral oval, and it is usually used as a proxy of Joule heating near an auroral arcs.

The 3-h mid-latitude geomagnetic index Kp (not shown here) reached the value of $8+$ at 18-21 UT on 22 June and at 03-06 UT on 23 June. This geomagnetic storm is the second largest to date in the 24th solar cycle after the St. Patrick's Day storm that occurred on 17-18 March 2015 (e.g., Cherniak and Zakharenkova 2015).

\section{Data and methodology \\ Database}

For the given research, we made use of all available permanent ground-based GNSS stations, which are able to track the GPS signals only and combined GPS and GLONASS signals. We use $\sim 5800$ ground-based GNSS stations gathered separately from several global and regional GNSS networks: the International GNSS Service (IGS), the University NAVSTAR Consortium (UNAVCO), the Continuously Operating Reference System (CORS), the Scripps Orbit and Permanent Array Center (SOPAC), the EUREF Permanent GNSS network (EPN), the Federal Agency for Cartography and Geodesy (BKGE) in Germany, Institut Geographique National in France (IGN), the Swedish geodetic network (SWEPOS), the Finnish Reference Network (FGI-FinnRef), the NOANET GNSS Network in Greece, the Spanish GNSS Reference Stations Network (ERGNSS), the Natural Resources Canada's Canadian Geodetic Survey, the Canadian High Arctic 


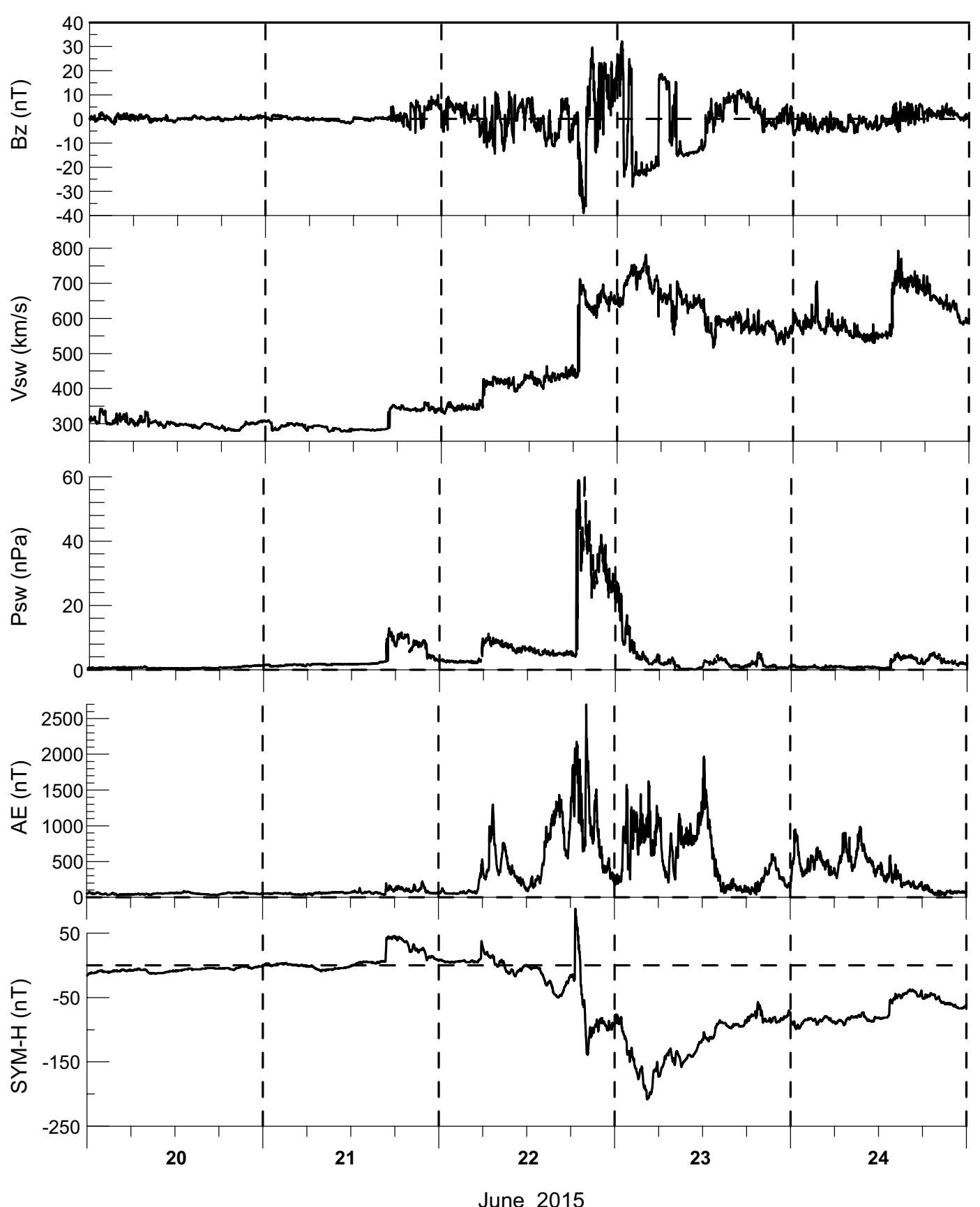

Fig. 1 Variations of the interplanetary and geomagnetic parameters during June 20-24, 2015, storm (from top to bottom): IMF Bz component, velocity and dynamic pressure of the solar wind, auroral electrojet index AE and index of geomagnetic activity SYM-H

Ionospheric Network (CHAIN), the Brazilian Network for Continuous Monitoring (RBMC), the Red Argentina de Monitoreo Satelital Continuo (RAMSAC CORS), the Australian Regional GNSS Network (ARGN) and the New Zealand Government GNSS CORS.

Figure $2 \mathrm{a}$ shows an actual distribution of the permanent GNSS stations within the latitudinal range of $30^{\circ}-90^{\circ}$ in both hemispheres for June 2015 . We should note that there are more than 4800 permanent GNSS stations located at the mid- and high latitudes of the northern hemisphere, while an overall number of all available stations in the southern hemisphere is about 1000. Thus, the distribution of the ground-based receivers is rather sparse in the southern hemisphere, dominated by oceans. 

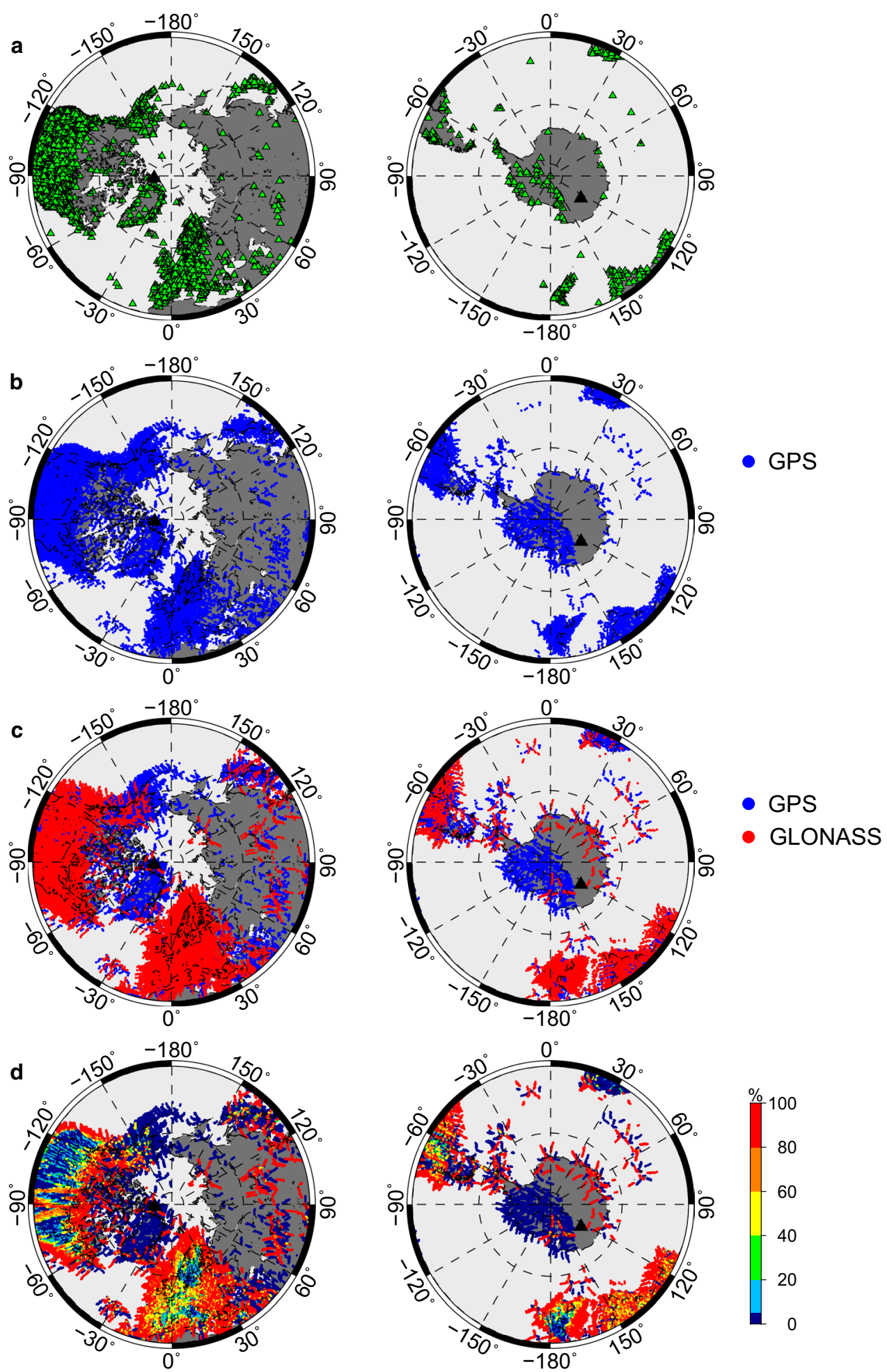

Fig. 2 Data coverage over the northern (left) and southern (right) hemispheres within geographic latitudes of $30^{\circ}-90^{\circ}$ : a distribution of GNSS stations; examples of the data coverage accumulated during $1 \mathrm{~h}$ by $\mathbf{b}$ GPS signals only and $\mathbf{c}$ combined GPS and GLONASS signals, $\mathbf{d}$ percentage contribution of GLONASS data in each cell. Black triangle indicates the location of the geomagnetic pole 
That is why it is highly important to use any additional instrument or dataset in order to increase the number of the measurement points for a more accurate representation of the ionospheric plasma density structure in the high-latitude regions.

Figure $2 \mathrm{~b}$ demonstrates an example of the data coverage accumulated during $1 \mathrm{~h}$ by all available stations tracking the GPS signals; blue dots show location of the ionosphere pierce points (IPPs) on links from a groundbased receiver to a GPS satellite. Figure 2c presents the same maps of the registered GPS data with the superimposed GLONASS measurements (red color dots). It is clearly seen that the GLONASS data coverage is very good and dense over the regions where the ground-based stations can track both systems simultaneously, e.g., the USA, Europe, Australia and Argentina. Thus, in these regions the use of the GLONASS can potentially increase the number of available measurements by a factor of 1.5-2 as comparing with using the GPS only. But impact of the GLONASS is more valuable in the regions with the sparse ground-based stations, particularly, at high latitudes of both hemispheres, the Asian sector, as well as rare islands with GNSS stations. Figure $2 \mathrm{~d}$ shows the percentage contribution of the GLONASS measurements to each data cell. Here, the dark blue color indicates cells with the GPS measurements only, while orange and red colors depict cells where GLONASS can contribute more than $60-80 \%$ to total GNSS measurements. It is clearly seen that the dense networks, which support both types of signals (GPS and GLONASS), can significantly gain in a total number of measurements per a spatial cell/bin by adding the GLONASS system.

\section{Methodology}

We processed GPS and GLONASS measurements derived from more than 6000 ground-based GNSS stations. These data are freely available for users and distributed in the raw RINEX (The Receiver Independent Exchange Format) format (Gurtner 1994). Sampling rate of the raw data is usually $30 \mathrm{~s}$ for the majority of stations. For a case of high-rate measurements (e.g., $1 \mathrm{~s}$ ), the data were resampled to $30 \mathrm{~s}$ for uniformity.

There are several steps of the GNSS data processing. Firstly, we calculate the slant total electron content (TEC), defined as the line integral of the electron density from a ground-based receiver to a GPS satellite. This slant line is called a line of sight (LOS). Due to the frequency dependent ionospheric impact on radio signals, dual-frequency phase measurements at two carrier frequencies can provide very accurate relative slant TEC values (e.g., Blewitt 1990; Hofmann-Wellenhof 2001). Thus, slant TEC (sTEC) can be defined from equation (Eq. 1):

$$
\text { sTEC }=\left(\frac{L_{1}}{f_{1}^{2}}-\frac{L_{2}}{f_{2}^{2}}\right) \cdot \frac{f_{1}^{2} \cdot f_{2}^{2}}{f_{1}^{2}-f_{2}^{2}} \cdot \frac{c}{K}
$$

where $f_{1}=1575.42 \mathrm{MHz}$ and $f_{2}=1227.60 \mathrm{MHz}$ are carrier frequencies of the GPS signals; $L_{1}$ and $L_{2}$ are the corresponding phase paths of radio signals at $f_{1}$ and $f_{2}$; $K=40.3 \mathrm{~m}^{3} / \mathrm{s}^{2}$; and $c=3 \times 10^{8} \mathrm{~m} / \mathrm{s}$ is the speed of light in vacuum.

We should note here another important difference between GPS and GLONASS systems apart from the different orbit configuration (inclination, altitude). Each GPS satellite transmits radio signals at two fixed carrier frequencies $f_{1}=1575.42 \mathrm{MHz}$ and $f_{2}=1227.60 \mathrm{MHz}$. Unlike GPS, all GLONASS satellites transmit the same code at different frequencies. These frequencies can be derived from the equations below:

$$
\begin{aligned}
& f_{1}=(1602.0+0.5625 n) \mathrm{MHz} \\
& f_{2}=(1246.0+0.4375 n) \mathrm{MHz}
\end{aligned}
$$

where $n$ is the frequency channel number $(n=-7$, $-6,-5, \ldots, 0, \ldots, 6)$. GLONASS accomplishes system operation (24 satellites and only 15 channels) by having antipodal satellites transmit on the same frequency (ICD-GLONASS 2008). Antipodal satellites are in the same orbit plane separated by $180^{\circ}$ in argument of latitude (Jeffrey 2015). This is possible because the paired satellites will never appear at the same time in view of an operational ground-based receiver. These channel numbers change from time to time due to shorter lifetime of the GLONASS satellites and launch of new satellites; thus, the corresponding channel numbers for each GLONASS satellite should be regularly verified according to an actual GLONASS almanac (Russian IAC PNT 2016). So, processing of GLONASS measurements should be conducted quite accurately regarding determination of the operational frequencies for each satellite.

After determination of sTEC values along LOS for all visible GPS and GLONASS satellites during $24 \mathrm{~h}$, we applied algorithms for detection and correction of cycle slips and loss-of-lock and removed outliers. The elevation cutoff mask of $25^{\circ}$ is used here to minimize the multipath effects in the sTEC variations. The carrier phase measurements can be also affected by cycle slips which are sudden changes in the integer phase ambiguity due to the phase tracking loop within the receiver. The cycle slip may be as small as one or a few cycles, or contain millions of cycles. Here, we use two approaches for cycle slip detection-the widelane Melbourne-Wübbena linear combination (Melbourne 1985; Wübbena 1985) and method of differencing geometry-free phase observations with estimation of the rate of TEC changes similar 
to that of Horvath and Crozier (2007). Then, all derived sTEC values are geolocated using a single-layer model approach, when sTEC along the LOS is referred to the point of LOS intersection (IPP) with the thin ionospheric layer located at $350 \mathrm{~km}$ altitude.

As an ionospheric irregularity can be characterized by measuring its impact on the phase of the received GPS signal, Pi et al. (1997) introduced into usage for ground-based GPS observations two GPS-based indices: ROT and ROTI. Rate of TEC change (ROT) is the timederivative of TEC and is considered as a measure of the phase fluctuation activity. Rate of TEC Index (ROTI) represents a standard deviation of the ROT over a selected time interval. The ROTI characterizes the severity of the GPS phase fluctuations and detects the presence of the ionospheric irregularities, which can be characterised by the TEC spatial gradient. Today, the ROT/ROTI indices, derived from the ground-based GPS data, are widely used in near-real-time services of space weather monitoring (e.g., NICT 2016; SWACI 2016 and described by Jakowski et al. 2006; Miyake and Jin 2010) and in investigations of the ionospheric irregularities occurrence at high- and low-latitude regions (e.g., Cherniak and Zakharenkova 2015). Here, we propose to extend the standard GPS database by the combined GPS and GLONASS observations.

ROT is determined by taking the ratio of the difference between the slant TEC values at two successive times to time interval (Eq. 4):

$$
\mathrm{ROT}=\frac{\mathrm{sTEC}_{k}^{i}-\mathrm{sTEC}_{k-1}^{i}}{t_{k}-t_{k-1}}
$$

where $i$ is a GPS/GLONASS satellite and $t_{k}$ is an epoch time. The ROT values are calculated and then detrended for all LOS with elevation angle over $25^{\circ}$. ROT is calculated in units of TECU $/ \mathrm{min}, 1 \mathrm{TECU}=10^{16} \mathrm{el} / \mathrm{m}^{2}$, for each visible satellite over a ground-based station. The ROTI represents the standard deviation of ROT for a 5-min interval using a running window mode (Eq. 5):

$$
\text { ROTI }=\sqrt{\left\langle\text { ROT }^{2}\right\rangle-\langle\text { ROT }\rangle^{2}}
$$

Features and limitations of the different sampling rates and running window intervals and their impact on the ROTI estimates were discussed by Jacobsen (2014).

Further, to analyze the high-latitude ionospheric irregularities occurrence and temporal development, we construct, from the multi-site GNSS database, the ROTI maps in the geographic coordinate frame. These ROTI maps with a polar view projection were constructed with high spatial resolution for the latitudinal range of $30^{\circ}-90^{\circ}$ in both northern and southern hemispheres. All ROTI values derived from the GPS and GLONASS data along all visible satellite passes were averaged and binned into cells of $1^{\circ} \times 1^{\circ}$ resolution in geographic latitude and longitude. No interpolation was used here; the empty cells with no data or with less than 50 points per cell were marked as blank ones. The temporal interval was selected as $1 \mathrm{~h}$.

\section{Results and discussion \\ Comparison of GPS and GLONASS measurements in polar region}

Figure 3 presents two examples of GPS and GLONASS measurements for two ground-based stations PFRR $\left(65.1^{\circ} \mathrm{N} ; 147.4^{\circ} \mathrm{W}\right)$ and $\mathrm{MAC} 1\left(54.5^{\circ} \mathrm{S} ; 158.9^{\circ} \mathrm{E}\right)$ located in the polar regions of the northern and southern hemispheres, respectively. Left panels show the geometry of the IPPs distribution of the GPS (blue points) and GLONASS (red points) observations over these stations (black dot) over $24 \mathrm{~h}$ on June 22,2015 . It is clearly seen that GLONASS observations are able to cover a wider area in a corresponding poleward direction than that of the GPS coverage ability. As we have explained above, it is due to the higher inclination of the GLONASS satellite orbits $\left(65^{\circ}\right.$ vs. $55^{\circ}$ of GPS). That is why the GLONASS satellites can be tracked by the same GNSS operational receiver at much higher latitudes than the GPS ones at the same time. Middle and right panels of Fig. 3 show the ROT and ROTI values calculated separately from GPS and GLONASS measurements. The left axis of these graphs indicates the PRN (pseudo-random noise)-satellite number. We note an intensification of the ionospheric irregularities activity started at $\sim 07$ UT at both polar GNSS stations. These increases correlate well with three periods of the increased AE index of 06-11, 15-17 and 18-21 UT on June 22, 2015 (see Fig. 1d). An important feature to note is that behavior of the ROT/ROTI values and their amplitude are very similar between GPS and GLONASS measurements. In other words, they are affected in the same way. That is why contribution of the GLONASS data with different geometry and spatial location can significantly complement the GPS observations. Thus, the fluctuation measurements (ROT/ROTI) from GPS and GLONASS are compatible and consistent with each other and can be combined into a composite result such as a ROTI map.

Two-dimensional combined GPS and GLONASS ROTI maps Figures 4 and 5 show the hourly ROTI maps constructed in a polar geographic projection over the northern and southern hemispheres correspondingly for a quiet day of June 20, 2015, and two disturbed days of June 22 and 23, 2015 . Based on the combined GPS and GLONASS observations, these ROTI maps were constructed with 

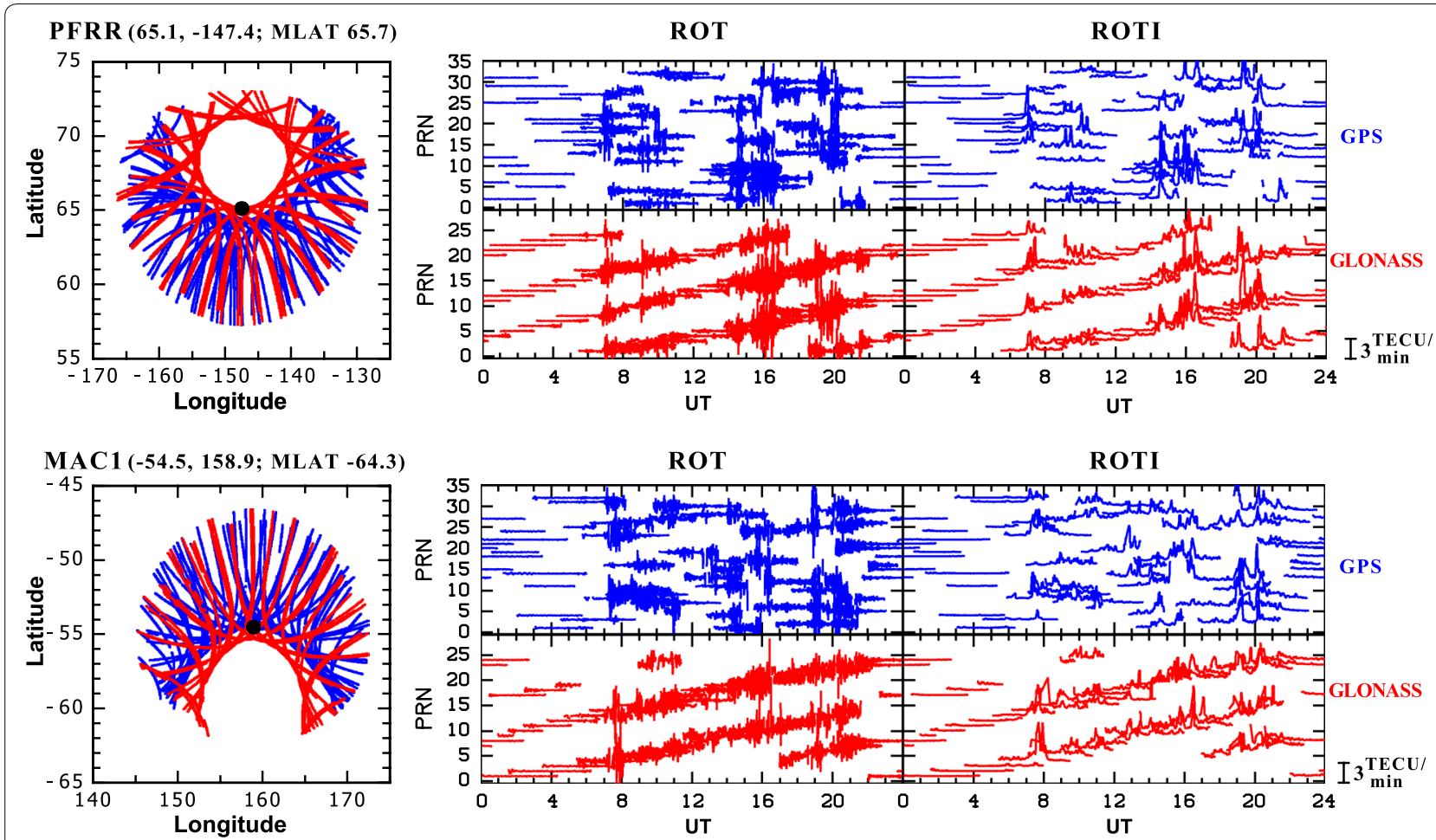

Fig. 3 Examples of GPS and GLONASS measurements for two ground-based stations PFRR $\left(65.1^{\circ} \mathrm{N} ; 147.4^{\circ} \mathrm{W}\right)$ and MAC1 $\left(54.5^{\circ} \mathrm{S} ; 158.9^{\circ} \mathrm{E}\right)$ on the disturbed day of June 22, 2015: the distribution of IPP projections over a single station (left panel) with a black dot indicating the location of the station; the derived ROT variation (middle panel) and ROTI variation (right panel) along all visible satellites. GPS measurements are shown as blue, GLONASS measurements as red, while the left axis shows the satellite number (PRN)

high spatial resolution $\left(1^{\circ} \times 1^{\circ}\right.$ in geographic latitude and longitude) and time interval of $1 \mathrm{~h}$. The map for $00 \mathrm{UT}$ means that here we averaged data from 00:00 to 00:59 UT. Full set of the hourly ROTI maps is available in the supporting information (Additional file 1: S1, Additional file 2: S2, Additional file 3: S3).

We should note that the North American and European sectors have an essentially better data coverage than other regions in the northern and southern hemisphere (see Fig. 2a, e), that is why the hourly ROTI maps reveal their best data coverage and higher resolution over these regions. Overall, the mid- and high latitudes of the northern hemisphere exhibit proper coverage by the GPS and GLONASS observation within a wide longitudinal range of $140^{\circ} \mathrm{W}-50^{\circ} \mathrm{E}$. Apart from GNSS, there is no other radio-based instrument able to provide such data coverage from the ground.

These hourly ROTI maps demonstrate the dynamics of the ionospheric irregularities in a geographic coordinate frame. The ROTI values marked by dark blue color (ROTI below $0.2 \mathrm{TECU} / \mathrm{min}$ ) represent very weak or an absence of the ionospheric irregularities. The ROTI values marked by orange and red colors (ROTI $>0.8-1.0$ $\mathrm{TECU} / \mathrm{min}$ ) correspond to the occurrence of the intense ionospheric irregularities in this sector. Analysis of the ROTI maps for a quiet day of June 20, 2015 (Figs. 4a, 5a) revealed the very quiet situation over the polar regions in both hemispheres with rather weak irregularities occurring in the vicinity of the geomagnetic poles.

The first noticeable changes in the irregularities distribution pattern appeared after $07-08$ UT on June 22, 2015, initiated by the second CME arrival and the first intensification of auroral activity (see Fig. 1). The most intense irregularities in both hemispheres were observed after 16 UT on 22 June. Very high ROTI values $(>0.8-1 \mathrm{TECU} / \mathrm{min}$ ) were found to form an oval-like structure around the northern geomagnetic pole. Further, the GNSS-derived irregularity oval expanded equatorward during several hours, and its equatorial edge was detected in the North American sector at $\sim 45^{\circ} \mathrm{N}-50^{\circ} \mathrm{N}$ geographic latitude for more than $2-3 \mathrm{~h}$. The highest ROTI intensity values in this oval-like feature occurred mainly over Northern Europe. We should also emphasize that the intense ionospheric irregularities were observed over Southern Europe at $\sim 25^{\circ} \mathrm{N}-40^{\circ} \mathrm{N}$ geographic latitude during the main phase of the storm at 20-04 UT (Figs. 4; Additional file 2: S2, Additional file 3: S3). These irregularities were associated with the occurrence of 







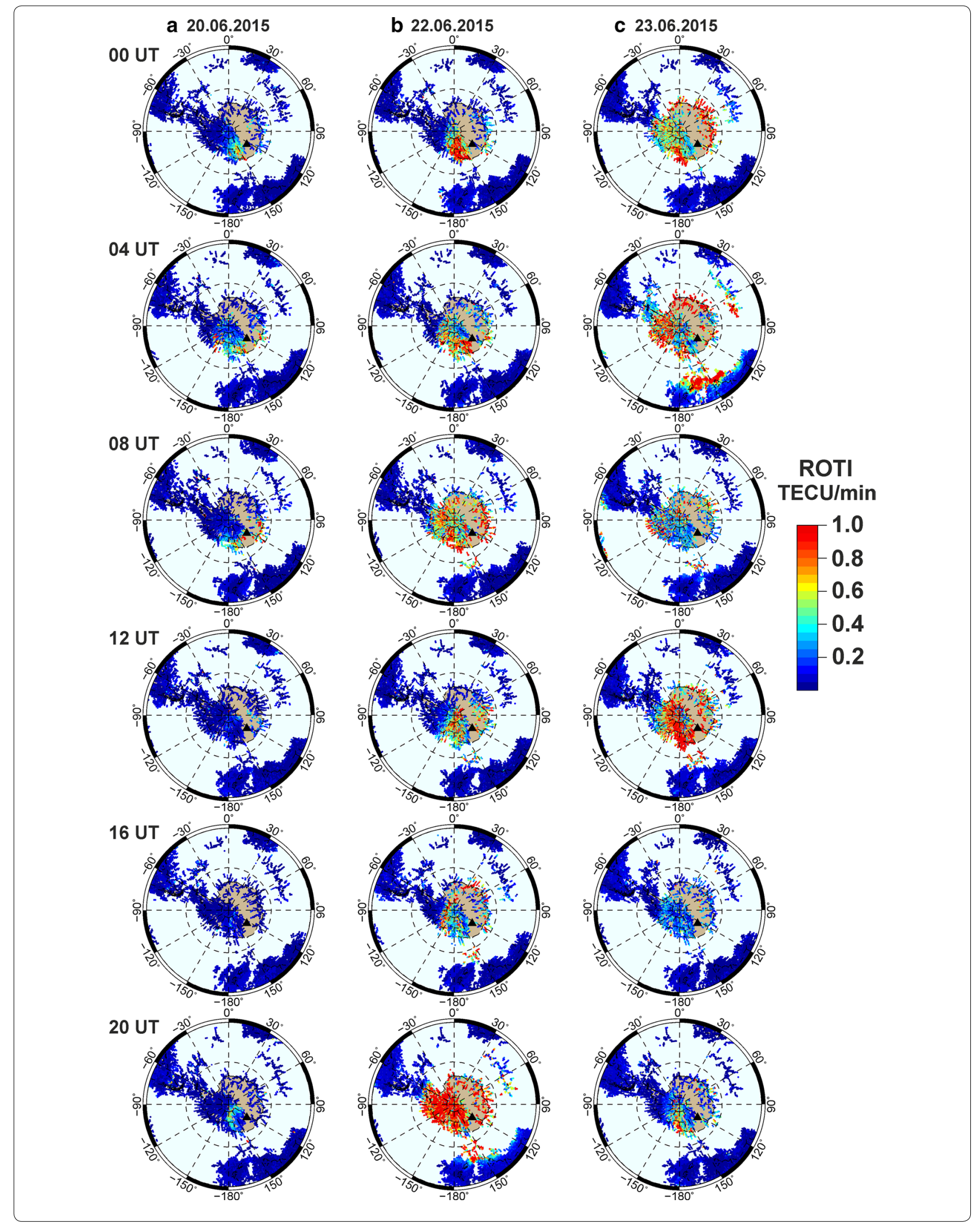


(See figure on previous page.)

Fig. 5 Two-dimensional ROTI maps derived from the combined GPS and GLONASS observations over the southern hemisphere for a quiet day of June 20 and disturbed days of b June 22 and $\mathbf{c}$ June 23, 2015. Each vertical row shows the ROTI maps constructed with $1 \mathrm{~h}$ resolution and shown here with 4-h interval. Black dot depicts location of the geomagnetic pole. Full set of the two-dimensional maps over both hemispheres with 1-h time interval is available in the supporting materials as Additional file 1: S1, Additional file 2: S2, Additional file 3: S3 respectively to June 20 , June 22 and June 23 of year 2015

plasma bite-outs and equatorial plasma bubbles in the postsunset sector (20-04 UT) over low latitudes of Western Africa after the prompt penetration electric fields at 18-20 UT on June 22, 2015 (for more details see Cherniak and Zakharenkova 2016b).

The ionospheric irregularities occured during the June 2015 geomagnetic storm and depicted by the combined GPS and GLONASS observations have impact on the navigation system performance. The WAAS System Performance Analysis Report indicated that during the June 22-23 it was observed a reduction in Localizer Performance with Vertical Guidance (LPV) and Localizer Performance with Vertical Guidance to $200 \mathrm{ft}$ decision height (LPV200) coverage provided by WAAS in the continental US (CONUS), Alaska, and Canada (Wanner 2015). In these regions, there were observed the strong ionospheric irregularities related with the auroral particles precipitations, more detailedly described in next subsections. Moreover, the highly intense irregularities lead to a performance degradation of the European Geostationary Navigation Overlay Service (EGNOS). It is very interesting to note that an impact of the ionospheric irregularities occurrence on the GNSS performance in the European sector was observed not only at high latitudes (irregularities related with particles precipitations and ionospheric patches formation), but also at Southern Europe and the Mediterranean region (irregularities related with the storm-time plasma depletions of equatorial origin, i.e., plasma bubbles development) (Cherniak and Zakharenkova 2016b).

At high latitudes, generation and evolution of the ionospheric irregularities were associated with auroral particle precipitation after the CMEs arrival and further development of the main phase of this geomagnetic storm.

Figure 5 presents the evolution of ionospheric irregularities over the southern hemisphere. Here, it is also possible to estimate differences in the occurrence, intensity and location of the ionospheric irregularities. We note the occurrence of the high ROTI values close to the geomagnetic pole, which can be associated with the ionospheric irregularities generated by particle precipitation to the dayside cusp (e.g., Kelley et al. 1982; Weber et al. 1984). Ionospheric irregularities of such origin are usually developed even under the quiet geomagnetic conditions (see Fig. 5a).
One can recognize the pronounced intensifications and equatorward expansion of the irregularity zone. We should note that due to an essentially poorer coverage by the GNSS data over the southern hemisphere (due to ocean area predomination), such effects were observed in the limited longitude range of $30^{\circ} \mathrm{E}-170^{\circ} \mathrm{E}$ (mainly over GNSS stations in Antarctica, as well as in the New Zealand and Australia networks and islands in the Pacific Ocean). This limited coverage in the southern hemisphere does not allow to depict the whole pattern of the ionospheric irregularities behavior using the ROTI maps with $1 \mathrm{~h}$ resolution in such detail as in the northern hemisphere. Despite this limitation, the 1-h ROTI maps revealed clearly an evolution of the ionospheric irregularities zone with time. Figure $5 \mathrm{~b}$ demonstrates the occurrence of a narrow oval-like or ring-like structure around the geomagnetic pole at $16 \mathrm{UT}$, and then, this zone expanded and covered the whole Antarctica continent (20 UT). Further, the irregularities zone expanded equatorward and reached New Zealand and Southern Australia with much smaller ROTI values near the south magnetic pole (Fig. 5c, 04 UT). In general, the evolution of the irregularities oval is rather similar to the evolution observed in the northern hemisphere. However, we should take into account the seasonal (winter to summer) differences between the hemispheres. Laundal and Østgaard (2009) explain this asymmetry in terms of interhemispheric currents related to seasons-the difference in ionospheric conductivity is expected to give rise to different auroral intensities in the two hemispheres as well as when the IMF has a significant Bx and By component. All those conditions were observed during the 22-23 June geomagnetic storm.

\section{Meridional slices of the combined GPS and GLONASS ROTI maps}

In order to compare the time evolution of the storminduced ionospheric irregularities during the geomagnetic storm of June 22-23, 2015, we selected the most representative and data covered longitude sectors in both hemispheres and analyzed the meridional slices of the GPS and GLONASS ROTI maps. To increase temporal resolution, we calculated the ROTI maps with 15 min sampling rate instead of $1 \mathrm{~h}$ as presented in "Twodimensional combined GPS and GLONASS ROTI maps" 


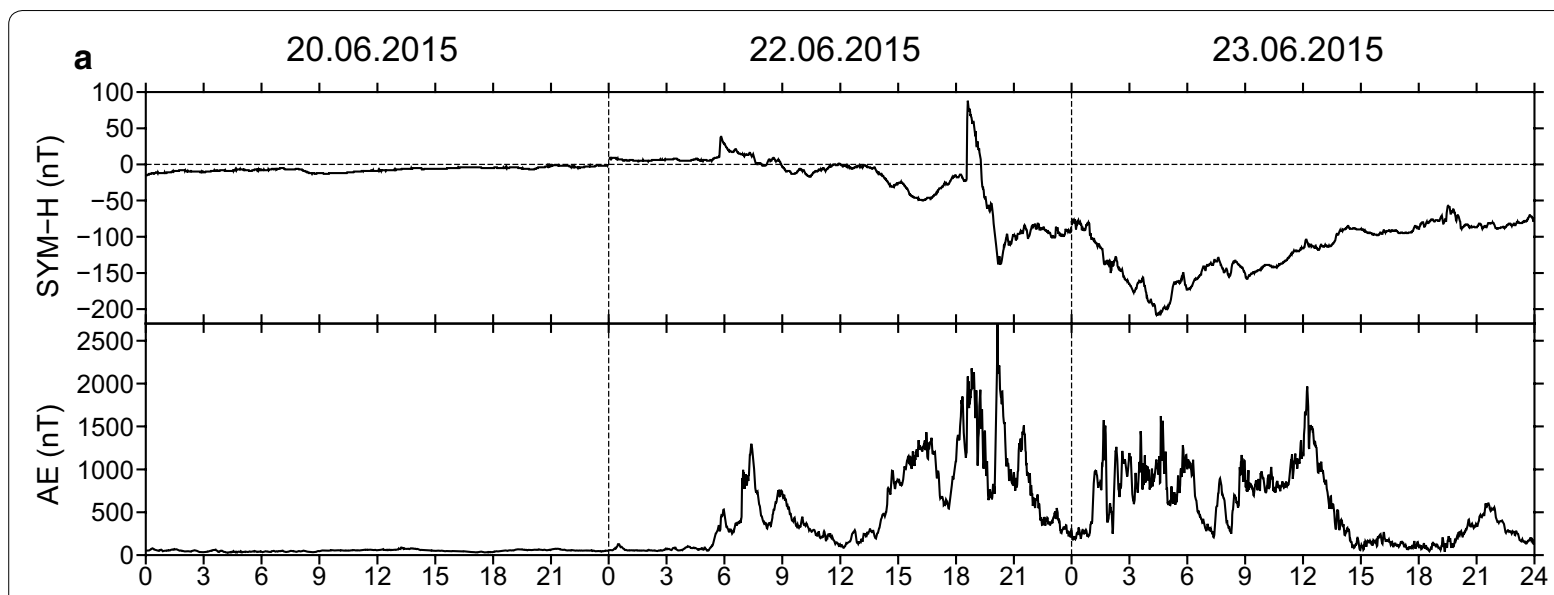

b Longitude $85 \mathrm{~W}$, North American Sector

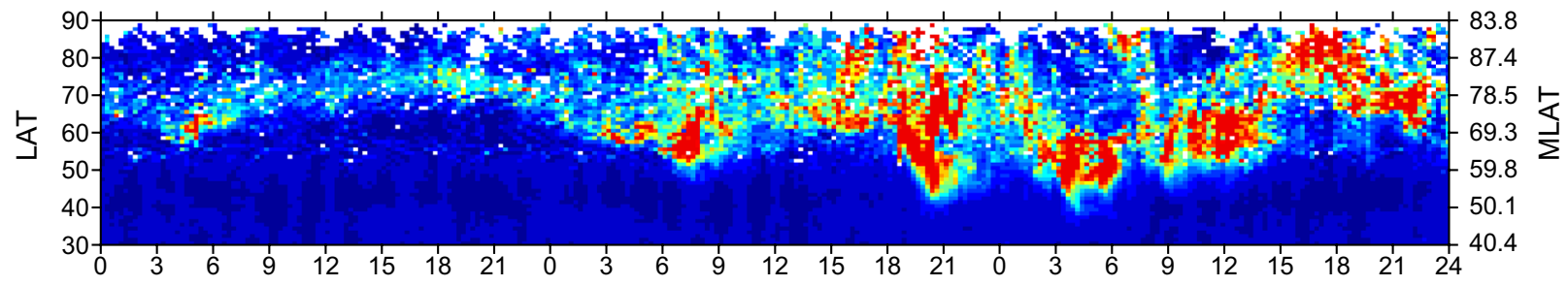

C Longitude 20E, European Sector

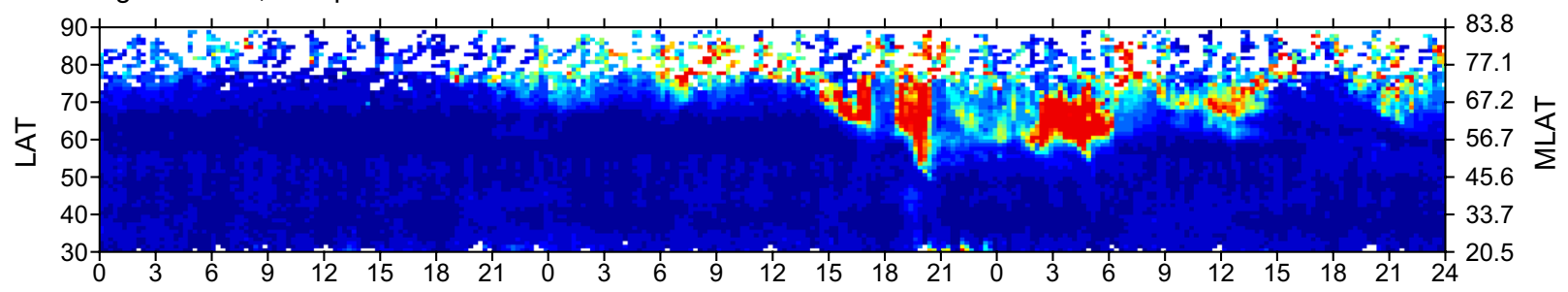

d Longitude 70W, South American Sector

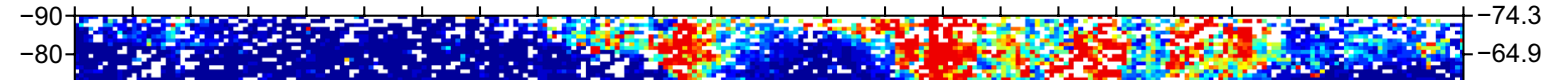

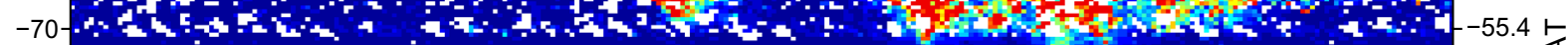

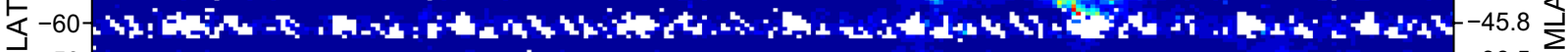

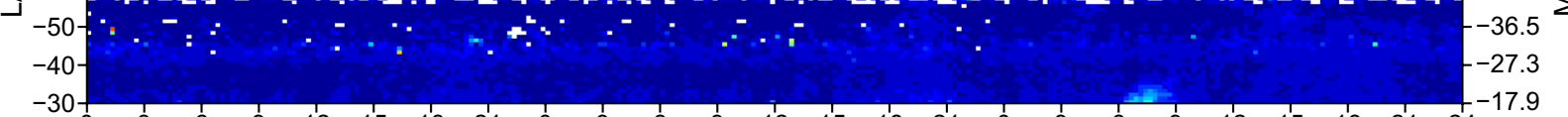

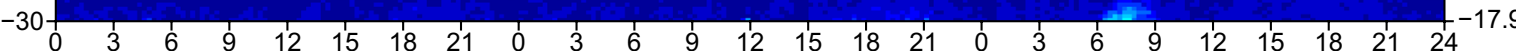

e Longitude 150E, Australian Sector

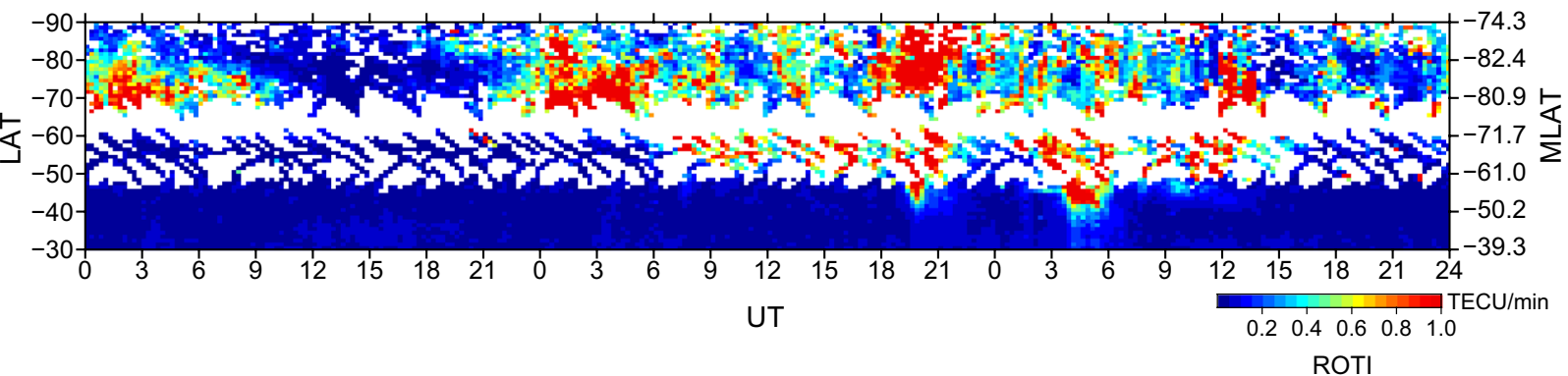

Fig. 6 Comparison of $\mathbf{a}$ the SYM-H and AE indices with 1 min resolution and ROTI perturbations with 15 min resolution as a function of geographic latitude and time, evaluated along b $85 \mathrm{~W}$ in North America, c 20E in Europe, d 70W in South America and e 150E in the Australian sector during June 20 and June 22-23, 2015. The left vertical axis for b-e graphs shows geographic latitudes, right axis - the corresponding corrected geomagnetic latitudes 
section. Figure 6 shows a comparison of the SYM-H (1-min resolution Dst) and auroral electrojet (AE) indices with the meridional slices of ROTI perturbations, evaluated along the following longitudes: $85^{\circ} \mathrm{W}$ in North America, $20^{\circ} \mathrm{E}$ in Europe, $70^{\circ} \mathrm{W}$ in South America and $150^{\circ} \mathrm{E}$ in Australian sector during quiet day of 20 June and two disturbed days of June 22-23, 2015. The meridional slices are constructed as an average of the ROTI perturbations within the band of $\pm 5^{\circ}$ around a selected geographical longitude and plotted as a function of geographic latitude and time. We consider the geographic latitudinal range of $30^{\circ}-90^{\circ}$ in both hemispheres. The left vertical axis in Fig. 6b-e shows geographic latitudes, and the right axis shows the corresponding corrected geomagnetic latitudes. It is necessary to note that due to the difference between the geomagnetic and geographic poles, the meridional slices in Fig. 6b, e crossed the latitude of the geomagnetic pole.

For the quiet day of June 20, 2015, the meridional slices of the northern hemisphere ROTI maps shown in Fig. 6b-e revealed an occurrence of the ionospheric irregularities at high latitudes only within $70^{\circ}-80^{\circ}$ MLAT (close to cusp region) in the American and Australian sectors, probably induced by soft particles precipitation. The first noticeable peak in the ROTI-derived irregularities distribution was recognized after $\sim 06$ UT on June 22,2015 , in all considered latitudinal sectors. This period corresponded to the second CME arrival at 05:45 UT, rapid changes of the SYM-H index and the first intensification of the auroral activity, represented by an $\mathrm{AE}$ index increase of $1300 \mathrm{nT}$ (see Fig. 6a). The next peak in ionospheric irregularities at high latitudes was observed at 15-17 UT. These processes were initiated by the IMF Bz southward turn and further increase in the auroral activity when AE rose to $\sim 1340 \mathrm{nT}$ and SYM-H dropped to $-70 \mathrm{nT}$. During this period, ionospheric irregularities were also registered simultaneously as equatorward as $70^{\circ}$ MLAT in North America and $65^{\circ}$ MLAT in Europe (Fig. 6b, c).

The most intense irregularities in the high and midlatitudes were found to occur at 18-22 UT on 22 June, which were associated with a new period of the increased auroral activity with two peaks of the AE index of $\sim 2180$ and $\sim 2700 \mathrm{nT}$, observed at 18:49 and 20:10 UT, respectively. During this period, the SYM-H increased to +88 $\mathrm{nT}$ and dropped rapidly to the value of $-139 \mathrm{nT}$ with dramatical rate of change of about $-130 \mathrm{nT} / \mathrm{h}$. As a result, during this period the high-latitude irregularities were detected as equatorward as $54^{\circ}$ MLAT in North America and $45^{\circ}$ MLAT in Europe. In the southern hemisphere, their signatures were found to extend equatorward to $-55^{\circ}$ MLAT in South America and $-50^{\circ}$ MLAT in the Australian sector (Fig. 6d, e). Additionally, we found that images from the SSUSI instrument onboard four DMSP satellites (available at http://ssusi.jhuapl.edu/data/edraur-anim//years/2015/173/EDR-AUR_LBHS_2015173.gif and placed as Additional file 4: S4) revealed an increase of the auroral activity on June 22, 2015, and an equatorward expansion of the aurora zone up to $50^{\circ}$ MLAT during 18-22 UT.

During the development of the second main phase (01:50-05:40 UT on 23 June), the intense ionospheric irregularities were continuously registered for a longer period $(4-5 \mathrm{~h})$ and they covered a latitudinal range from the polar region to $55^{\circ}$ MLAT in both sectors of the northern hemisphere (Fig. 6b, c) and to $-50^{\circ}$ MLAT in the southern hemisphere (Fig. 6d, e). Thus, signatures of the ionospheric irregularities, which were registered by the GPS and GLONASS signals and were analyzed by use of the meridional slice approach, reveal a strong linkage of their intensity and equatorward spatial expansion with auroral activity intensification, in particular represented by the AE and SYM-H indices. Such kind of analysis in the time-latitudinal domain allows us to estimate the principal dependencies of the onset of the ionospheric irregularities and their further development and evolution on space weather drivers. Future studies based on these approaches will allow to formalize these dependencies in the form of an empirical model of the ionospheric irregularities.

We can summarize that despite the unprecedented high number of stations deployed worldwide during the last $5-10$ years, the high-latitude regions (above $60^{\circ}$ MLAT) in both hemispheres depict a rather sparse coverage by the GPS and GLONASS ground-based observations compared to mid-latitudes. On the other hand, today the ground-based GNSS segment is the only data source able to provide multi-site ground-based observations with the best global coverage.

In this paper, we extend the use of the ROTI maps for analyzing ionospheric irregularities distribution. We demonstrate that the meridional slices of the ROTI maps can be effectively used to study the occurrence and temporal evolution of the ionospheric irregularities over selected geographical regions in quiet and especially geomagnetically disturbed periods. The meridional slices of geographical sectors characterized by a high density of the GPS and GLONASS measurements can represent spatio-temporal dynamics of the intense ionospheric plasma density irregularities with high resolution and they can be used for detailed studies of the space weather drivers on the processes of the ionospheric irregularities generation, their evolution and lifetimes.

We should emphasize that combination of the GPS and GLONASS signals allows to increase significantly the number of the transionospheric measurement links 
globally. As a result, it allows to improve the performance of the ionospheric irregularities monitoring in both the regions with sparse or dense permanent GNSS network coverage. In case of sparse networks (e.g., Northern Canada and Russia, Antarctica region and coastal zone in polar regions), the adjunction of the GLONASS-based measurements, due to the different constellation configuration as compare to the GPS one, allows to noticeably extend areas covered by the GNSS measurements and essentially increase a number of the available ionospheric piercing points. Particular benefits of GLONASS data at high latitudes can be earlier or better detection of the ionospheric disturbances related to the physical processes in the auroral region and polar cap, in particular through the combination with other instruments such as colocated magnetometers, all-sky cameras and coherent radars. As it is seen on Fig. 4, high and midlatitude areas in the American and European sectors are well covered by the combined GPS and GLONASS measurements without any significant "no data" gaps. For the regions with the dense GNSS networks, the extra use of the GLONASS data would increase a number of the available measurements by a factor of 1.5-2 as comparing with GPS only-for example, for the European region we can get $\sim 1,700,000-1,800,000$ IPPs per $1 \mathrm{~h}$. So, we can potentially construct the regional ROTI maps with an unprecedentedly high resolution up to $0.5^{\circ} \times 0.5^{\circ}$ in geographic latitude and longitude. Such detailed ROTI maps had been already successfully used for detection of the ionospheric irregularities related with the storminduced plasma depletion signatures in Europe (Cherniak and Zakharenkova 2016b).

\section{Conclusions}

Using a representative database of $\sim 5800$ ground-based GNSS stations located worldwide, we have investigated the occurrence of the high-latitude ionospheric plasma density irregularities during the geomagnetic storm of June 23-23, 2015. For the first time, the highresolution two-dimensional maps of ROTI perturbations were made using not only GPS but also GLONASS measurements.

We note that the current status of the GPS (US) system includes 32 satellites, while the GLONASS (Russia) system includes 24 satellites. The ongoing expansion of the GNSS system includes an increase (and/or renewal) in a satellite number for GPS and GLONASS, development of the European system Galileo (currently 15 satellites in orbit) and the Chinese system BeiDou (currently 18 satellites in orbit), as well as development of the regional Navigational Satellite Systems. Thus, more than 100 GNSS satellites could be available in the near future.
This expansion will increase the number of GNSS radio signal ray passes simultaneously scanning the Earth's ionosphere to an unprecedentedly high value! Signal diversity and redundant measurements, together with better geometry from multiple GNSS satellites, greatly improve the ability to refine the temporal and spatial resolution of the transionospheric measurements, as well as empirical and assimilative ionospheric models. It provides new opportunities to study the space weather impact on the ionosphere and GNSS navigation performance at a new level. Here, we presented the first results demonstrating the advantages of using several independent but compatible GNSS systems like GPS and GLONASS for improvement of the permanent monitoring of the high-latitude ionospheric irregularities.

\section{Additional files}

Additional file 1. The two-dimensional ROTI maps over northen and southern hemispheres with 1-h time interval for 20 June 2015, animated gif file.

Additional file 2. The two-dimensional ROTI maps over northen and southern hemispheres with 1-h time interval for 22 June 2015, animated gif file.

Additional file 3. The two-dimensional ROTI maps over northen and southern hemispheres with 1-h time interval for 23 June 2015, animated gif file.

Additional file 4. Proxy of auroral activity represented by the SSUSI instrument onboard DMSP satellites.

\section{Authors' contributions}

IC designed this study, analyzed the data and wrote the manuscript. IZ developed software for data processing and helped in interpretation of the data. All coauthors contributed to the revision of the draft manuscript and improvement of the discussion. Both authors read and approved the final manuscript.

\section{Author details}

${ }^{1}$ Space Weather Laboratory, Kharkiv, Ukraine. ${ }^{2}$ Space Radio-Diagnostic Research Center, University of Warmia and Mazury, 2 Oczapowskiego, Olsztyn 10-719, Poland. ${ }^{3}$ West Department of IZMIRAN, Kaliningrad, Russia.

\section{Acknowledgements}

We acknowledge use of the raw GPS and GLONASS data provided by IGS (ftp://cddis.gsfc.nasa.gov), UNAVCO (ftp://data-out.unavco.org), NOAA CORS (ftp://geodesy.noaa.gov/cors), SOPAC (ftp://garner.ucsd.edu), EPN (ftp://olggps.oeaw.ac.at), BKGE (ftp://igs.bkg.bund.de/euref/obs), IGN (ftp://rgpdata. ign.fr), SWEPOS (swepos.lantmateriet.se), FGI-FinnRef (euref-fin.fgi.fi), NOANET (www.gein.noa.gr), Natural Resources Canada (webapp.geod.nrcan.gc.ca), CHAIN (ftp://chain.physics.unb.ca/gps/), RBMC (ftp://geoftp.ibge.gov.br/

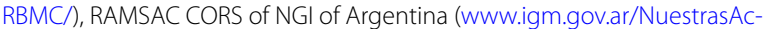
tividades/Geodesia/Ramsac/), ARGN (ftp://ftp.ga.gov.au) and NZ CORS (ftp:// geonet.org.nz) GNSS networks. We also thank IGS and CODE for providing GPS products (orbits, biases). The authors thank the NASA/GSFC's Space Physics Data Facility's OMNIWeb service, for providing OMNI data (http://omniweb. gsfc.nasa.gov/ow_min.html). We gratefully acknowledge the JHU/APL team for providing the DMSP SSUSI data products (http://ssusi.jhuapl.edu).

Competing interests

The authors declare that they have no competing interests. 


\section{Publisher's Note}

Springer Nature remains neutral with regard to jurisdictional claims in published maps and institutional affiliations.

Received: 17 August 2016 Accepted: 2 May 2017

Published online: 12 May 2017

\section{References}

Aarons J (1997) Global positioning system phase fluctuations at auroral latitudes. J Geophys Res 102:17219-17231. doi:10.1029/97JA01118

Aarons J, Lin B (1999) Development of high latitude phase fluctuations during the January 10, April 10-11, and May 15, 1997 magnetic storms. J Atmos Sol-Terr Phys 61:309-327

Baker DN et al (2016) Highly relativistic radiation belt electron acceleration, transport, and loss: large solar storm events of March and June 2015. J Geophys Res Space Phys 121:6647-6660. doi:10.1002/2016JA022502

Basu S, Mackenzie E, Basu Su (1988) Ionospheric constraints on VHF/UHF communications links during solar maximum and minimum periods. Radio Sci 23(3):363-378. doi:10.1029/RS023i003p00363

Blewitt G (1990) An automatic editing algorithm for GPS data. Geophys Res Lett 17:199-202

Cherniak I, Zakharenkova I (2015) Dependence of the high-latitude plasma irregularities on the auroral activity indices: a case study of 17 March 2015 geomagnetic storm. Earth Planets Space. doi:10.1186/s40623-015-0316-x

Cherniak I, Zakharenkova I (2016a) High-latitude ionospheric irregularities: differences between ground- and space-based GPS measurements during the 2015 St. Patrick's Day storm. Earth Planets Space 2016(68):136. doi:10.1186/s40623-016-0506-1

Cherniak I, Zakharenkova I (2016b) First observations of super plasma bubbles in Europe. Geophys Res Lett. doi:10.1002/2016GL071421

Gurtner W (1994) RINEX: the receiver-independent exchange format. GPS World 4:48-52

Hofmann-Wellenhof B (2001) Global positioning system: theory and practice. Springer, New-York

Hofmann-Wellenhof B, Lichtenegger H, Wasle E (2008) GNSS — global navigation satellite systems: GPS, GLONASS, Galileo, and more. Springer, Wien. doi:10.1007/978-3-211-73017-1

Horvath I, Crozier S (2007) Software developed for obtaining GPS-derived total electron content values. Radio Sci. 42:RS2002. doi:10.1029/2006RS003452

ICD-GLONASS (2008) Global navigation satellite system GLONASS interface control document, version 5.1. Russian Institute of Space Device Engineering, Moscow, Russia

Jacobsen KS (2014) The impact of different sampling rates and calculation time intervals on ROTI values. J Space Weather Space Clim 4:A33. doi:10.1051/swsc/2014031

Jacobsen KS, Andalsvik YL (2016) Overview of the 2015 St. Patrick's day storm and its consequences for RTK and PPP positioning in Norway. J Space Weather Space Clim 6:A9. doi:10.1051/swsc/2016004

Jakowski N, Stankov SM, Klaehn D, Becker C (2006) SWACl—a near-real time ionosphere service based on Ntrip technology. In: Proceedings of the Ntrip Symposium and Workshop "Streaming GNSS data via internet" BKG. Frankfurt am Main

Jakowski N, Mielich J, Borries C, Cander L, Krankowski A, Nava B, Stankov SM (2008) Large-scale ionospheric gradients over Europe observed in October 2003. J Atmos Sol-Terr Phys 70:1894-1903. doi:10.1016/j. jastp.2008.03.020

Jakowski N, Béniguel Y, De Franceschi G, Hernandez-Pajares M, Jacobsen KS, Stanislawska I, Tomasik L, Warnant R, Wautelet G (2012) Monitoring, tracking and forecasting ionospheric perturbations using GNSS techniques. J Space Weather Space Clim 2:A22. doi:10.1051/swsc/2012022
Jeffrey C (2015) An introduction to GNSS: GPS, GLONASS, Galileo and other global navigation satellite systems. NovAtel Publisher, Calgary, Canada

Kelley MC, Vickrey JF, Carlson CW, Torbert R (1982) On the origin and spatial extent of high-latitude F region irregularities. J Geophys Res 87(A6):4469-4475

Keskinen MJ, Ossakow SL (1983) Theories of high-latitude ionospheric irregularities: a review. Radio Sci 18:1077-1091. doi:10.1029/RS018i006p01077

Laundal KM, Østgaard N (2009) Asymmetric auroral intensities in the Earth's Northern and Southern hemispheres. Nature 460:491-493. doi:10.1038/ nature08154

Melbourne WG (1985) The case for ranging in GPS based geodetic systems. In: Proceedings of the 1st international symposium on precise positioning with the global positioning system, Rockville, pp 373-386

Miyake W, Jin H (2010) Near-real time monitoring of TEC Over Japan at NICT (RWC Tokyo OF ISES). In: Advances in geosciences A 6-Volume Set Volume 21: Solar Terrestrial (ST). Published by World Scientific Publishing, Singapore

NICT (2016) Service NICT GEONET quasi-realtime TEC maps over JAPAN (segweb.nict.go.jp/GPS/QR_GEONET/index_e.html). As Accessed on 15 Aug 2016

Pi X, Mannucci AJ, Lindqwister UJ, Ho CM (1997) Monitoring of global ionospheric irregularities using the worldwide GPS network. Geophys Res Lett 24:2283

Prikryl P, Jayachandran PT, Mushini SC, Richardson IG (2012) Toward the probabilistic forecasting of high-latitude GPS phase scintillation. Space Weather 10:S08005. doi:10.1029/2012SW000800

Prikryl P, Jayachandran PT, Mushini SC, Richardson IG (2014) High-latitude GPS phase scintillation and cycle slips during high-speed solar wind streams and interplanetary coronal mass ejections: a superposed epoch analysis. Earth Planets Space 66:62. doi:10.1186/1880-5981-66-62

Russian IAC PNT (Information and Analysis Center for Positioning, Navigation and Timing) (2016) FTP server (ftp://ftp.glonass-iac.ru/MCC/ALMANAC/). As Accessed on 15 Aug 2016

SWACI (2016) The Space Weather Application Center lonosphere (http://www. swaciweb.dlr.de/data-and-products/?no_cache $=1 \& \mathrm{~L}=1 /$ ). As Accessed on 15 Aug 2016

Tiwari R, Strangeways HJ, Tiwari S, Ahmed A (2013) Investigation of ionospheric irregularities and scintillation using TEC at high latitude. Adv Space Res 52:1111-1124. doi:10.1016/j.asr.2013.06.010

Tsunoda RT, Haggstrom I, Pellinen-Wannberg A, Steen A, Wannberg G (1985) Direct evidence of plasma density structuring in the auroral $\mathrm{F}$ region ionosphere. Radio Sci 20:762-784

Valladares CE, Villalobos J, Sheehan R, Hagan MP (2004) Latitudinal extension of low-latitude scintillations measured with a network of GPS receivers. Ann Geophys 22:3155-3175. doi:10.5194/angeo-22-3155-2004

van der Meeren C, Oksavik K, Lorentzen D, Moen Jl, Romano V (2014) GPS scintillation and irregularities at the front of an ionization tongue in the nightside polar ionosphere. J Geophys Res Space Phys 119:8624-8636. doi:10.1002/2014JA020114

Wanner B (2015) DR \#127: effect on WAAS from lono Activity on March 17-18, 2015, WAAS Technical Report at the WAAS Test Team web-page, 2015. Accessed 03 April 2017. http://www.nstb.tc.faa.gov/Discrepancy\%20 Reports\%20PDF/DR\%20127\%20Effect\%20on\%20WAAS\%20from\%20 lono\%20Activity\%20March\%2017\%202015.pdf

Weber EJ, Buchau J, Moore J, Sharber J, Livingston R, Winningham J, Reinisch B (1984) F layer ionization patches in the polar cap. J Geophys Res 89(A3):1683-1694

Wübbena G (1985) Software developments for geodetic positioning with GPS using TI 4100 code and carrier measurements. In: Proceedings of the 1st international symposium on precise positioning with the global positioning system. Rockville, pp 403-412 